\title{
Perfect Pizza - Credit Card Processing Decisions
}

\author{
Gail Kaciuba, Ph.D., St. Mary's University, San Antonio, USA
}

\begin{abstract}
This case is based on a consulting project the author conducted with a credit card processing company, although the names and the numbers have been adjusted for use in the classroom. The case describes the nature of the credit card processing industry and asks students to prepare worksheets and graphs to determine credit card costs from the merchant's perspective and revenues from the processor's perspective. The workbook tasks require the use of absolute and relative cell-referencing and the MAX function, and also contain formatting issues for spreadsheets and graphs. The students are also asked to write a memo and to respond to several questions about decision making by the merchant and by the processor. One series of open-ended questions asks students to reflect on uncertainty, information bias, and risk aversion as elements of the decision making process.
\end{abstract}

Keywords: Spreadsheets; Graphs; Writing Skills; Analytical Skills; CVP Analysis; Decision Making

\section{INTRODUCTION TO THE CREDIT CARD PROCESSING INDUSTRY - MERCHANT'S PERSPECTIVE}

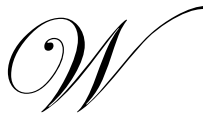

hen a merchant wants the ability to accept credit cards from its customers, it must make arrangements with a credit card processing company. A credit card processing company is the intermediary between the merchant and the bank that processes the credit card payments (called the processing bank). A merchant must negotiate the fees with the credit card processing company, and, in most cases, cannot deal directly with the processing bank.

In addition to the purchase or leasing costs for the credit card terminal, there are three components of the merchant's monthly cost of credit card processing services. The first is known as the processing rate. This rate is the percentage of the credit card sale amount that the merchant pays to the processing bank. If the merchant has the customer's card in her hand, she can swipe the card through the credit card terminal and pay what is known as the "swipe rate". On the other hand, if the merchant does not physically have the customer's credit card (e.g. if a customer places an order via phone), the merchant must physically enter the customer's credit card information into the credit card terminal. Since there is a higher chance for fraud on these transactions, credit card processing companies charge an additional percentage for these "keyed-in" transactions.

The second component of the merchant's processing cost is known as the transaction cost. This is the amount charged to the merchant for each credit card transaction (regardless of the dollar amount), whether it is swiped or keyed-in. Finally, at the end of each month, the processing bank sends the merchant a monthly statement summarizing all credit card transactions and processing costs for the month. The third component of the merchant's credit card processing costs is the fee for this monthly statement.

In addition to the above three components of costs that a merchant will incur on credit card processing, some processing banks impose a monthly minimum on the sum of the first two components of the monthly processing cost. This minimum is usually stated as a dollar amount. For example, if the processing company has a \$25 monthly minimum, then the merchant will pay at least \$25 per month for the sum of the first two components (processing rate charges plus transaction costs) of her credit card processing costs. Note that the monthly statement fee is $\underline{\text { not }}$ included in the computation of costs subject to the monthly minimum. 


\section{PERFECT PIZZA'S DECISION}

Nancy started a pizza parlor years ago in Wisconsin and it was very successful. She now sells "Perfect Pizza" franchises to others and no longer runs any of the individual pizza parlors. Perfect Pizza, Inc. makes money from the sale of the franchises and receives a percentage of the monthly gross revenues from each location.

Most of these parlors are generally very small neighborhood restaurants, with limited seating capacity, which means that the cost to start a new location is not exorbitant. This has allowed many entrepreneurs to open a store, and the number of Perfect Pizza locations is increasing rapidly throughout Wisconsin. Some stores are mostly 'dine-in' restaurants, and Nancy estimates that they get about $70 \%$ of their revenue from customers who eat at the restaurant. The other $30 \%$ of the revenue comes from pizzas that are delivered to the customers. Credit card sales from dine-in customers would be subject only to the swipe rate, and credit card sales to delivery customers would be subject to the swipe rate plus the incremental keyed-in rate.

A few stores have no seating capacity and get about $90 \%$ of their revenue from delivering pizzas and about $10 \%$ from customers who come in to pick up a pizza. Again, credit card sales to delivery customers would be subject to both the swipe and keyed-in rates, but credit card sales to customers who pick up their orders would be subject only to the swipe rate.

Nancy does everything she can to help her franchisees become successful. She knows that most locations do not accept credit cards, but she believes that sales will increase when the stores do accept credit cards. Nancy contacted a credit card processing company known as Miracle Merchant Services (MMS) about the cost of credit card processing services. Stan, the owner of MMS, told Nancy that each of her franchise owners could choose between three plans that MMS offers. Table 1 summarizes these three plans.

Table 1 - Credit Card Processing Plans Offered by MMS

\begin{tabular}{|llccccc|}
\hline & Swipe Rate & $\begin{array}{c}\text { Add'l \% for Keyed- } \\
\text { in Transactions }\end{array}$ & $\begin{array}{c}\text { Transaction } \\
\text { Cost }\end{array}$ & $\begin{array}{c}\text { Monthly } \\
\text { Statement Fee }\end{array}$ & $\begin{array}{c}\text { Monthly } \\
\text { Minimum }\end{array}$ \\
\cline { 2 - 7 } Plan A & $2.1 \%$ & $0.8 \%$ & $26 \phi$ & $\$ 12$ & None \\
Plan B & $1.07 \% 1^{\text {st }} \$ 17,600 *$ & $0.8 \%$ & $18 \phi$ & $\$ 15$ & $\$ 200$ \\
Plan C & $1.6 \%$ & $0.8 \%$ & $14.5 \phi$ & $\$ 10$ & $\$ 115$ \\
\hline
\end{tabular}

* In Plan B, the $1.07 \%$ swipe rate is valid only for credit card sales up to and including $\$ 17,600$. After that, the swipe rate is $2.75 \%$ on all sales over $\$ 17,600$.

In order to help her franchisees determine which plan is best, Nancy gathered information about sales transactions at some of her franchise stores, as well as other small pizza parlors whose owners she knows. She discovered that the average sale is $\$ 32$. Nancy would like to present credit card processing cost information to her existing and potential franchisees in the most useful way possible.

\section{REQUIREMENTS (PART I - MERCHANT DECISIONS)}

You must turn it both electronic and hard copies of your workbook and your document. Put your name in a footer in each spreadsheet in your workbook, and insert a footer in your Word document with your name and page numbers. It is important to make sure that all documents are appropriately formatted for viewing on the screen and for printing out. Spelling, grammar, punctuation, sentence structure, tone, and format are also extremely important in the scoring of your written answers.

1. Prepare a workbook and name it "YourNameMerchant". Name the first tab "Dine-in Costs". Give the worksheet an appropriate heading at the top, and then summarize the details (from Table 1) of Plans A, B, and $\mathrm{C}$ so that you can reference these cells in the formulas you create in your worksheet. Use the following column headings on your worksheet: 
- $\quad$ \# of transactions

- Sales - swiped

- $\quad$ Sales - keyed-in

- Total sales

- Total credit card costs, Plan A

- Total credit card costs, Plan B

- Total credit card costs, Plan C

The rows in the first column should start at zero transactions, and then go up to 750 transactions in increments of 25. Create a formula to quickly populate this transactions column, so you don't have to enter all of the transaction quantities. Then in the zero transactions row, create formulas for each cell in that row. Use appropriate absolute and relative cell referencing so that you only write formulas for that row. There's a helpful six and a half minute video on YouTube at http://www.youtube.com/watch?v=71DlJFe6d8k on this topic, or just Google 'absolute versus relative cell referencing Excel', as there are many resources to help you. Then copy your first row of formulas down to all rows.

The formulas you type in the zero transaction row should work for all transaction quantities, with an exception for Plan B, which I'll cover in a moment. Since there's a minimum for two of the plans, you'll need to use the 'MAX' function. YouTube has a tutorial about this and other functions at http://www.youtube.com/watch?v=fkGgThSVtdE. For Plan B, it's a bit more complicated, since the processing rate changes (this happens in the 575 transactions row). It is certainly possible to create a function for the total Plan B costs in the zero transactions row that will correctly calculate Plan B's costs for all levels of transactions. But, for this assignment, it's easier and acceptable to create a new formula for Plan B costs starting in the 575 transaction row and copy this formula the rest of the way down the column. If you're unsure whether your formulas are correct, pick a couple of transaction quantities and calculate the total costs by hand to make sure you get the same numbers.

Make sure your worksheet is nicely formatted, and that the columns for the total plan costs display two decimals, but the columns for sales dollars display zero decimals. Pay attention to the cell justification, and the way it will print out. Hit print preview and see if you believe this is a worksheet you'll be proud to say you created.

2. Prepare a line graph, and display it on the second tab. Name this tab "Dine-in Costs Graph". Label the Y axis as $\$$ of processing costs and the $\mathrm{X}$ axis as $\$$ of total credit card sales. Make sure that the graph is wellformatted, titled, and includes a legend with the names of the three plans. Excel graphs rarely look very nice without additional formatting. The three lines that should be displayed on the graph are the total credit card processing costs under MMS Plans A, B, and C, respectively. You may need to reformat the three series in case the user of the graph prints it on a black and white printer. Make sure that the labels on the $\mathrm{X}$ axis are sales dollars, not integers, and that you include a legend. Finally, the labels on the $\mathrm{X}$ and $\mathrm{Y}$ axes should display in whole dollars with no decimals.

3. To submit your response to this requirement, open a Word document and name it YourNameMerchant'. Describe the credit card processing costs for each plan individually in your own words. In your description, identify whether the cost function is linear or piecewise linear. Identify the portion of costs for each plan that are fixed and those that are variable. For the variable costs, identify the cost driver. If there's more than one cost driver, explain how we're able to use a graph with only one $\mathrm{X}$ axis. For piecewise linear cost functions, identify the sales level in dollars at which the slopes change.

4. Look at your Dine-in Costs graph and note how many times the three lines cross each other. (Hint: this should occur four times.) These are the 'points of indifference' between the plans. Find these four indifference points. I suggest writing out a formula for the plans' costs at that level of transactions, using X for the number of transactions. Then solve for X, and convert your answer to sales dollars. Show me your calculations and the formulas you used. Look at both your graph and the spreadsheet to see if your calculations make sense. 
5. Look at your Dine-in Costs graph and your calculations for requirement 4 to help you respond to this question. Write a memo from Nancy to all of her franchisees that have dine-in parlors about accepting credit cards. Include in your memo the pros and cons of a franchise accepting credit cards, an analysis of the three MMS processing plans, and a summary of Nancy's advice as to which plan might be best. Be specific (i.e. include sales levels) in the recommendation. Use appropriate memo format, and remember that this is a writing assignment so grammar, spelling, sentence structure, format, and style are all important. A really good memo would have a small picture of the graph embedded in it. Remember, Nancy believes that credit card acceptance increases sales, so the memo should include an analysis of the pros and cons of accepting credit cards from that viewpoint. But Nancy is an honest person, so she will mention that credit cards may not increase sales overall for some stores in certain circumstances (can you figure out what these circumstances are?).

6. A new Perfect Pizza is opening in rural Kenosha, and will have 20 four-person tables for seating customers. Twenty tables is rather large compared to the typical parlor, and the franchisee predicts that this parlor will have monthly credit card sales of about $\$ 16,000$. In your Word document, answer the following questions. This is still a writing assignment so grammar, spelling, sentence structure, format, and style are all important.

a) List the uncertainties that the Kenosha franchisee faces when he tries to decide which of the three MMS processing plans he should choose, explain why each is an uncertainty, and how the uncertainty might be resolved, if at all. A bullet point format is acceptable for this question.

b) What assumptions will the Kenosha franchisee need to make as he considers this decision? A bullet point format is also acceptable for this question, as long as you carefully describe the assumption and the reasons the franchisee must make that assumption.

c) What bias (one way or another) might there be in the information that the franchisee is using to make this decision? What is the source of the information, and why would that source tend to produce biased information? What direction would you expect the bias, if any, to be? Which information has zero bias in it? Write this up in paragraph form.

d) Suppose that you are the new Kenosha franchisee. Can you think of any biases that you may have that will influence your decision in any way? Describe these, or tell me why you have no bias that would affect the decision. Write this up in paragraph form.

e) Ignore the Kenosha pizza parlor decision when you answer this requirement. Tell me how you personally feel about risk (not financial risk, but risk in general). Are you a risk taker or a risk avoider? Give me a couple of examples. How about financial risk? Again, give me a couple examples. Finally, would you consider yourself an optimist or a pessimist? Explain.

f) As the new Kenosha franchisee, which MMS plan would you adopt? Explain. How does this fit in with your analysis of your level of risk aversion and optimism?

7. Select both tabs of your workbook (use the control key to highlight both), right click and choose 'move or copy'. Check the 'create a copy' box and choose to place the copied tabs at the end of the workbook. You now have two new worksheets in your workbook with the same names as the first but followed by (2). Rename these two tabs 'Delivery Costs' and 'Delivery Costs Graph', respectively.

a) Change the assumptions on the Delivery Costs tab from $70 \%$ swiped/30\% keyed-in to $10 \%$ swiped/90\% keyed-in. The rest of your worksheet will now automatically adjust for these new assumptions because your formulas included cell references to the given information at the top. Adjust the heading on the Delivery Costs spreadsheet so you can distinguish it from the first spreadsheet when it is printed out. Also, adjust the title of the Delivery Costs graph.

b) Compare your two graphs and describe some differences you notice between them. Explain why you see these differences. 


\section{THE PROCESSOR'S PERSPECTIVE}

This part of the case is about the decision making of Stan, owner of MMS. When MMS puts together a processing plan for a customer, Stan must determine which processing bank he will use for this customer. When Stan designed Plans A, B, and C for Perfect Pizza, he chose a particular processing bank for each plan. Remember that a credit card processing company is the middleman between the merchant and the processing bank, and hence purchases the services from the processing bank. The cost of these services to MMS is known as MMS' "buy rate". Any difference between the processing costs paid by the merchant and the buy rates of MMS is paid to MMS (by the processing bank) in a monthly residual check. MMS' buy rates for Plans A, B, and C are shown in Table 2. Note that the minimums do not affect MMS' residual check received from the processing bank. For example, if a merchant under Plan $C$ has zero credit card transactions in one month, the merchant will incur $\$ 115$ in total processing charges. However, MMS would not receive a residual check from the processing bank for this merchant.

Table 2 - MMS Buy Rates for Plans A, B, and C

\begin{tabular}{|llccccc|}
\hline & Swipe Rate & $\begin{array}{c}\text { Add'l \% for Keyed- } \\
\text { in Transactions }\end{array}$ & $\begin{array}{c}\text { Transaction } \\
\text { Cost }\end{array}$ & $\begin{array}{c}\text { Monthly } \\
\text { Statement Fee }\end{array}$ & $\begin{array}{c}\text { Monthly } \\
\text { Minimum }\end{array}$ \\
\cline { 2 - 7 } Plan A & $1.69 \%$ & $0.7 \%$ & $20 \phi$ & $\$ 10$ & None \\
Plan B & $1.05 \% 1^{\text {st }} \$ 17,600^{*}$ & $0.7 \%$ & $14.5 \phi$ & $\$ 13$ & $\$ 200$ \\
Plan C & $1.49 \%$ & $0.7 \%$ & $12 \phi$ & $\$ 8$ & $\$ 115$ \\
\hline
\end{tabular}

* In Plan B, the $1.05 \%$ buy swipe rate is valid only for credit card sales up to and including $\$ 17,600$. After that, the buy swipe rate is $1.59 \%$ on all sales over $\$ 17,600$.

\section{REQUIREMENTS (PART II - CREDIT CARD PROCESSOR DECISIONS)}

As in Part I of this case, you must turn it both electronic and hard copies of your workbook and your document. Again put footers in each file, and the footer of the Word document should have page numbers. Formatting and writing continue to be important for this part of the case.

8. Select the first two (Dine-in) tabs of your workbook (use the control key to highlight both), right click and choose 'move or copy'. Check the 'create a copy' box and choose to place the copied tabs in a new workbook. Name this workbook YourNameMMS. Rename the two tabs 'Dine-in Revenue' and 'Dine-in Revenue Graph', respectively. Insert some rows in the given information at the top of the worksheet and type in the MMS buy rates from Table 2. Retain the assumptions that $70 \%$ of credit card transactions are swiped, $30 \%$ are keyed-in, and the average credit card sale is $\$ 32$. Change the headings on the spreadsheet as necessary to reflect that this worksheet will calculate the revenue MMS will get from one Perfect Pizza Dine-in restaurant. Adjust the formulas to calculate this revenue. Use cell referencing as before. You may need to edit the footer as well.

9. Edit the title on your Dine-in Revenue graph and adjust the scale on the $\mathrm{Y}$ axis to have a lower maximum that's closer to the maximum revenue shown on the worksheet. Edit the footer on the graph, if necessary.

10. Like you did in Part I of this case, select the first two tabs of your MMS workbook, copy them and paste them at the end of the workbook. Change the tabs' names to 'Delivery Revenue' and 'Delivery Revenue Graph', respectively. Change the "70/30" assumption to "10/90". Adjust the spreadsheet and graph headings as necessary.

11. Include your responses to the questions below in a Word document named YourNameMMS.

a) Compare your Dine-in Revenue graph to your Dine-in Costs graph. Note some differences and explain why those differences exist. Keep your answer under three or four sentences.

b) Compare your Dine-in Revenue graph to you Delivery Revenue graph. Note some differences and explain why those differences exist. Keep your answer under three or four sentences. 
c) Suppose a typical delivery franchise with an estimated $\$ 17,000$ per month of credit card sales contacts Stan about MMS' services. Which Plan would Stan like to sell the franchise? Is that one the best choice for the franchise? What is the next-best plan for MMS? Is this one a good choice for the franchise? Would Stan be pleased if the franchise chose its lowest cost plan? Discuss.

d) Do you think that MMS allows its customers to changes plans from month to month, or do you think that MMS tells its customers they must choose a plan and remain with it for some period of time? Explain your answer. Does this have anything to do with uncertainty or risk aversion?

\section{TEACHING NOTES}

A comprehensive set of solutions and instructor guidance is available from the author.

\section{AUTHOR INFORMATION}

Gail Kaciuba, Ph.D. is the Emil Jurica Professor of Accounting, Bill Greehey School of Business, St Mary's University, One Camino Santa Maria, San Antonio, TX 78228. E-mail: gkaciuba@stmarytx.edu 